\title{
MedOBIS: biogeographic information system for the eastern Mediterranean and Black Sea
}

\author{
C. Arvanitidis ${ }^{1, *}$, V. D. Valavanis ${ }^{1}$, A. Eleftheriou ${ }^{1}$, M. J. Costello ${ }^{2}$, S. Faulwetter ${ }^{1}$, \\ P. Gotsis ${ }^{1}$, M. S. Kitsos ${ }^{3}$, I. Kirmtzoglou ${ }^{3}$, A. Zenetos ${ }^{4}$, A. Petrov ${ }^{5}$, B. Galil ${ }^{6}$, \\ N. Papageorgiou ${ }^{1}$
}

${ }^{1}$ Institute of Marine Biology and Genetics, Hellenic Centre for Marine Research, PO Box 2214, Iraklion, 71003 Crete, Greece

${ }^{2}$ Leigh Marine Laboratory, University of Auckland, PO Box 349, Warkworth, New Zealand

${ }^{3}$ School of Biology, Laboratory of Zoology, Aristotelian University of Thessaloniki, 51424 Thessaloniki, Greece

${ }^{4}$ Institute of Oceanography, Hellenic Centre for Marine Research, PO Box 712, Anavyssos, 19013 Attiki, Greece

${ }^{5}$ Institute of Biology of the Southern Seas, Sevastopol 99011, Ukraine

${ }^{6}$ National Institute of Oceanography, Oceanographic and Limnological Research, PO Box 8030, Haifa 31081, Israel

\begin{abstract}
Recent online initiatives in sharing marine biological data, such as the European Register of Marine Species (ERMS) and the Ocean Biogeographic Information System (OBIS), identified gaps in data from the eastern Mediterranean and Black Sea. Such data are now being collected, formatted and disseminated by MedOBIS (the Mediterranean Ocean Biogeographic Information System) initiative involving Greece, the Ukraine and Israel (test version available at: www.medobis.org). The aim is to develop a taxon-based biogeography database and online data server with links to survey and satellite environmental data. MedOBIS is currently undergoing 4 stages of development, namely, data assembly, formatting, analysis and dissemination. The primary features of the MedOBIS application are its offline GIS (Geographic Information Systems) data formatting capabilities and its online Java- and JavaScript-enabling data server with taxon-based search, mapping and data downloading capabilities. It is an independent source of biological and environmental data, as well as an online GIS tool designed to facilitate access to historical and current data by marine researchers. As more data become available and are inserted into the system, MedOBIS will function as the eastern Mediterranean and Black Sea node of EurOBIS (the European node of the international OBIS initiative, part of the 'Census of Marine Life').
\end{abstract}

KEY WORDS: Marine biodiversity $\cdot$ Data management $\cdot$ GIS $\cdot$ OBIS

\section{INTRODUCTION}

The international and interdisciplinary nature of ecosystem research and management can be facilitated by the Internet and associated activities in biodiversity informatics. The free dissemination of valuable historical and current biological, environmental and genetic information is contributing to the establishment of an interdisciplinary research platform targeted towards information integration at regional and global scales and to the development of information-based management schemes.
Development of systems such as OBIS (Ocean Biogeographic Information System, www.iobis.org/), OBIS-SEAMAP (Spatial Ecological Analysis of Megavertebrate Populations, http://seamap.env.duke.edu/), FIGIS (FAO Fisheries Global Information System, www.fao.org/fi/figis/) and aphia (North Sea species register, www.vliz.be/vmdcdata/aphia/) facilitate the study of anthropogenic impacts on threatened species. At the same time they enhance our ability to test biogeographic and biodiversity models, support modelling efforts to predict distribution changes in response to environmental change and provide new opportuni- 
ties for public outreach. In addition, such online database systems allow the development of management practices that are based on synthetic analyses of interdisciplinary data (Schalk 1998, Laitinen \& Neuvonen 2001, Decker \& O'Dor 2002, Marshall 2002, Tsontos $\&$ Kiefer 2002, Babu 2003).

An analysis of the availability of data, expertise and identification guides concerning marine species was conducted (e.g. Costello 2000, Costello et al. 2001, 2006, in this Theme Section) as part of the European Register of Marine Species (ERMS). These activities identified the eastern Mediterranean and Black Sea as gaps in the availability of marine data. Similarly, OBIS identified the need to establish a marine biodiversity informatics infrastructure for the same region and the associated North African countries. A number of web sites provide marine biodiversity information for the Mediterranean and Black Sea region, namely, the Commission Internationale pour l'Exploration Scientifique de la Méditerranée (IESM) atlas of exotic species (www.ciesm.org/ online/atlas/index.htm), a site on Mediterranean sea turtles (www.euroturtle.org/), the Mediterranean oceanic database on oceanographic research (modb.oce.ulg. ac.be/), Blackseaweb (www.blackseaweb.net/), a site on the ecology of Mnemiopsis leidyi (www.issg.org/ database/species/ecology.asp? $\mathrm{si}=95 \& \mathrm{fr}=1 \&$ sts $=$ ) and the IODE (www.iode.org). However, none of these provides information concerning the distribution and abundance of marine species in the region. To this end, the development of a new online marine biological information system called MedOBIS (Mediterranean Ocean Biogeographic Information System) was proposed.

MedOBIS aims to assemble, formulate, synthesise and disseminate marine biological data for the eastern Mediterranean and Black Sea regions, focusing on the reliability and longevity of historically surveyed data, the assembly of current and new information and the dissemination of raw and integrated biological and environmental data and future products through the Internet.

\section{DESCRIPTION OF MedOBIS}

There are 4 main stages in the current development of MedOBIS: data assembly, formatting, analysis and dissemination. The data assembly phase is based on the free contribution of biological data by various national and international scientific surveys in the region, as well as the processing of time series of remotely sensed and station environmental parameters. Assembled datasets include 839 stations with surveyed benthic biological data (Fig. 1). These data consist mainly of benthic species abundance and biomass for $>3000$ benthic organisms, seabed substrate types and for several environmental parameters. So far datasets have been assembled from 100 stations in the Ionian Sea, 569 stations in the Aegean Sea, 106 stations in the Black Sea and 64 stations in the Levatine Sea. These data cover the period 1937 to 2003; however, most of the data relate to the period 1986 to 1996 (Table 1). In addition, a variety of satellite and station environmental data on sea surface temperature, chlorophyll $a$, photosynthetically active radiation, salinity, sea level anomaly, precipitation and wind force and direction were compiled for the period 1985 to 2004. Sources of these data include international online data

Table 1. Overview of the current taxonomic, geographic and temporal coverage of the MedOBIS database

\begin{tabular}{|c|c|c|}
\hline Taxon & $\begin{array}{c}\text { No. of } \\
\text { taxa recorded }\end{array}$ & $\begin{array}{c}\text { No. of } \\
\text { observations }\end{array}$ \\
\hline \multicolumn{3}{|c|}{ Taxonomic records } \\
\hline Actinopterygii & 45 & 751 \\
\hline Annelida & 1093 & 9810 \\
\hline Anthozoa & 101 & 440 \\
\hline Ascidiacea & 54 & 350 \\
\hline Brachiopoda & 4 & 6 \\
\hline Bryozoa & 67 & 255 \\
\hline Cephalochordata & 1 & 20 \\
\hline Chaetognatha & 1 & 1 \\
\hline Chironomidae & 4 & 31 \\
\hline Crustacea & 1115 & 7930 \\
\hline Echinodermata & 118 & 954 \\
\hline Echiura & 2 & 54 \\
\hline Elasmobranchii & 3 & 43 \\
\hline Enteropneusta & 3 & 6 \\
\hline Foraminifera & 11 & 25 \\
\hline Gastrotricha & 1 & 4 \\
\hline Hydrozoa & 10 & 38 \\
\hline Mollusca & 1381 & 5400 \\
\hline Nematoda & 2 & 39 \\
\hline Nemertea & 13 & 187 \\
\hline Phoronida & 5 & 100 \\
\hline Platyhelminthes & 10 & 20 \\
\hline Pogonophora & 1 & 1 \\
\hline Porifera & 128 & 883 \\
\hline Priapulida & 1 & 3 \\
\hline Protozoa & 1 & 1 \\
\hline Pycnogonida & 6 & 34 \\
\hline Scyphozoa & 2 & 32 \\
\hline Sipuncula & 18 & 271 \\
\hline Total & 4201 & 27689 \\
\hline \multicolumn{3}{|c|}{ Geographic coverage } \\
\hline & \multicolumn{2}{|c|}{ No. of stations surveyed } \\
\hline Ionian Sea & \multicolumn{2}{|c|}{100} \\
\hline Aegean Sea & \multicolumn{2}{|c|}{569} \\
\hline Black Sea & \multicolumn{2}{|c|}{106} \\
\hline Levantine Sea & \multicolumn{2}{|r|}{64} \\
\hline \multicolumn{3}{|c|}{ Temporal coverage } \\
\hline Years & \multicolumn{2}{|c|}{ No. of stations surveyed } \\
\hline 1979-1980 & \multicolumn{2}{|c|}{167} \\
\hline 1991-2000 & \multicolumn{2}{|c|}{516} \\
\hline 2001-present & \multicolumn{2}{|c|}{128} \\
\hline \multicolumn{2}{|c|}{ 1937-2003 (total temporal coverage) } & 839 \\
\hline
\end{tabular}




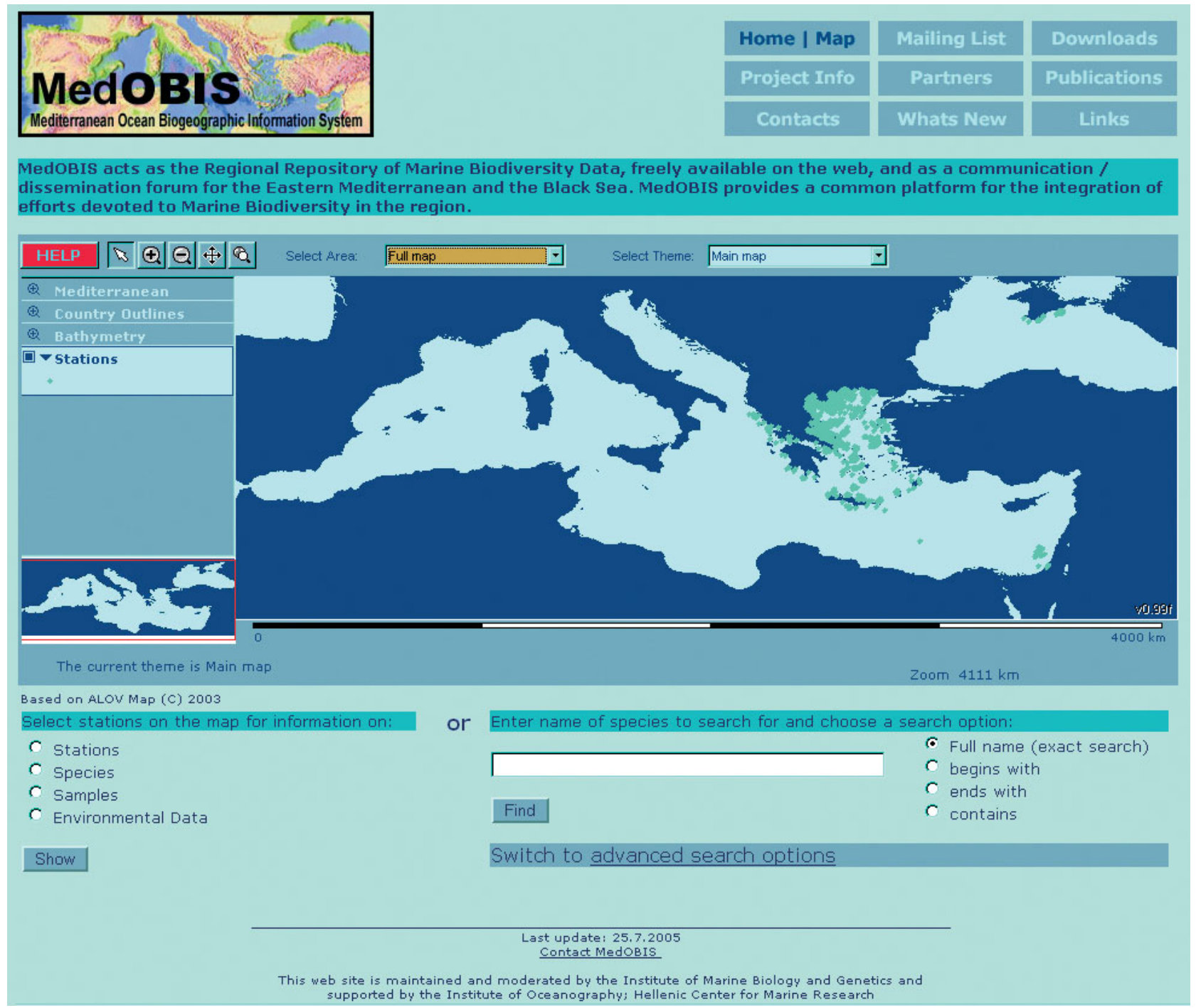

Fig. 1. MedOBIS system interface: spatial distribution of the current assemblage of biological survey stations in the eastern Mediterranean and Black Sea (total number of stations $=839$ ). The figure quality corresponds to that of the computer screen image

archives, such as the US National Aeronautics and Space Administration (NASA), the German Aerospace Agency (DLR) and the French European Remote Sensing (ERS) Processing and Archiving Facility (CERSAT). Currently, all assembled biological datasets are representative of the benthic communities existing in the eastern Mediterranean and Black Sea, while environmental datasets are representative of the entire Mediterranean Sea and the Black Sea. The long-term aim of the MedOBIS data assembly phase is to collect sufficient data to fully represent the changes and time intervals associated with the biological characteristics of the region. Since biological data from the eastern Mediterranean and Black Sea region are scarce in the relevant literature or, in many cases, remain undocumented, MedOBIS contributes a new geographic area to OBIS.
The data formatting stage of MedOBIS is based on a Geographical Information System (GIS) (ESRI 1994), under which all assembled datasets receive quality control and are processed under a common georeference scheme. The current quality control mechanisms include (1) the nomenclature control, based on readily available services on the web (ERMS, Species 2000 project) and on taxonomists' expertise; (2) the distribution of each species in the eastern Mediterranean and the Black Sea region, based on specialists' knowledge; and (3) the storage of the verified name in an extra attribute field - the initial name is kept to document any further changes. At a later stage, data quality control procedures will be formulated which will encompass database integrity constraints, automated plausibility checks and the synchronisation of species 
lists between the EurOBIS and MedOBIS databases. The GIS shapefile is the standard file format for linking the geographic coordinates of a point of interest with attributes such as measurements and specific characteristics. However, it was the complexity of the collected data that dictated the choice of the relational database management system (RDBMS) backend to store them. In this way, the GIS information layer includes the geographic coordinates of the stations as well as the station's identification number, which refers to relevant records in a MySQL database. The database fields are implemented according to the OBIS Schema 1.0, so that they will be accessible via the main OBIS portal through the DiGIR protocol (http://digir. sourceforge.net/) at a later stage of the project. Finally, satellite data are embedded in a GIS database as GIS regular grids (Valavanis et al. 1998, Valavanis 2002). The data formatting phase aims to contribute to the data interoperability issue through the production of commonly formatted GIS-ready data layers from currently scattered datasets stored in various and different formats; this is the first time such a task has been undertaken using biological data from the eastern Mediterranean and the Black Sea.

The MedOBIS data analysis phase is based on raster and vector datasets, integration through GIS and spatial analyses for the production of species distribution maps and identification of species-environment relations. Although still in its initial stage and currently only functional offline the data analysis phase has already produced several analytical results, especially on the mapping of ocean production processes and the biogeography of benthic polychaetes in the region (Arvanitidis et al. 2002, Valavanis et al. 2004a,b, in press). The data analysis phase aims to enhance the overall functionality of the system by providing a variety of spatial query tools for visualising relationships among species and their environment. Mapping of certain oceanic processes, such as marine productivity hotspots, mesoscale thermal fronts and productive gyres, will be introduced into the system as separate data layers. Thus, the user will be able to identify relationships of selected taxa to environmental gradients and processes (Fig. 2).

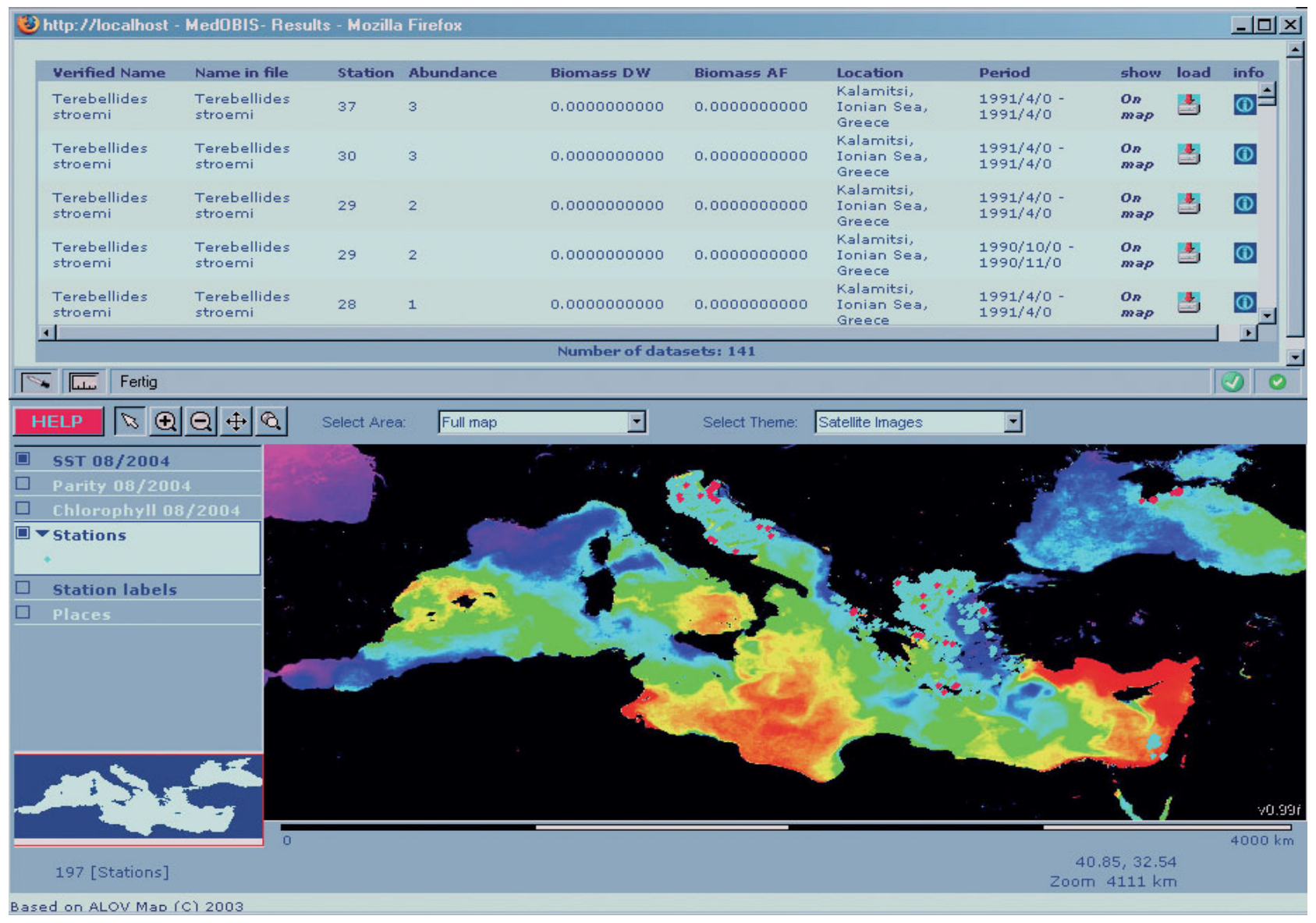

Fig. 2. MedOBIS system interface: selection of survey stations using search capability based on species' scientific names (information on $>3000$ species assembled for the eastern Mediterranean and Black Sea), superimposed on a map of sea surface temperatures. The figure quality corresponds to that of the computer screen image 
Finally, the dissemination phase is based on ALOV Map (www.alov.org/), a corporate project of ALOV Software and the Archaeological Computing Laboratory of the University of Sydney, Australia (Johnson 2004). ALOV Map is a free portable Java application for the publication of vector and raster maps on the Internet and for interactive viewing on web browsers. Its appearance and features can be controlled by XML files, by JavaScript, or by custom Java classes. Highly customised web pages can be created with this tool, including links from map objects to websites, querying attribute data and many interaction features for the user such as navigation, time filtering and working with multiple layers and thematic maps.

ALOV Map supports various data formats as sources, amongst them raster images, shapefiles and SQL (Structured Query Language) databases. A dedicated interface also allows the conversion of shapefiles to a database-readable format. The spatial data, which can thus be stored along with the biological data and taxa, can be referenced to their geographic location by performing SQL queries.

MedOBIS is based on a server running a suite of server application software programs, which are almost entirely open source. One of the benefits deriving from this type of software is that the data will not be locked up within a proprietary system. Consequently, the development of the software will not be governed by a single developer, and the ability to enhance the software and to provide interfaces for other similar projects focussing on the exchange of data will be unhindered. Apache (www.apache.org/), PHP (www.php. net), MySQL (htttp://www.mysql.org) and Tomcat (http://jakarta.apache.org/tomcat/) are components of the architecture. While ALOV Map itself is not open source, there has been a declaration from the producer that this is due to take place in the near future.

MedOBIS makes use of ALOV Map's client server mode. In this case, the connection between the applet and the database is managed by a servlet container hosted by Tomcat. This architecture allows an incremental loading of data to the client side, reducing download time and network traffic. PHP scripts are invoked to query the database; these search the data, display the results in a separate window and invoke a JavaScript code, which marks the matching stations on the map (Fig. 2).

Three approaches to obtaining information have been implemented to satisfy the need for customised queries. (1) For spatial queries, the user may select areas or single stations on the map and choose a predefined theme to obtain more information about the biological and environmental information available for these areas. (2) Taxonomic queries allow a search according to species names; the search mode displays a distribution pattern on the map and a detailed results window, which offers the user further navigation, metadata information and downloading possibilities, thus allowing the incorporation of additional environmental data. (3) Finally, an advanced interface is used to specify the request and even the output by taking into account environmental parameters, higher taxonomic groups, or certain time periods.

Additionally, a mailing list has been established that runs in parallel with the web site. It delivers information on marine biodiversity issues to approximately 600 Email addresses distributed not only in the eastern Mediterranean and Black Sea regions, but in other European and overseas countries as well. The mailing list (medobis@hcmr.gr) is also concepted to act as an electronic forum for the scientific community of the region and to contribute to the exchange of ideas and to the formulation of new projects in the future. The initiative is currently supported by the National Excellence Project of the Hellenic Centre for Marine Research on Marine Biodiversity. The centre shoulders responsibility for the sustainable maintenance of the MedOBIS initiative in the future, as part of its data management policy. This fact in itself ensures the sustainability of the MedOBIS system, which will be further developed through the introduction of online tools, metadata management, data entry user interfaces and customised data output.

Acknowledgements. This project was funded by the Niarchos Foundation through a grant to the 'Census of Marine Life' as part of its Ocean Biogeographic Information System and by the National Excellence Project of the Hellenic Centre for Marine Research in Marine Biodiversity. The authors wish to thank Mrs. $\mathrm{M}$. Eleftheriou for critical reading of the manuscript.

\section{LITERATURE CITED}

Arvanitidis C, Bellan G, Drakopoulos P, Valavanis V, Dounas C, Koukouras A, Eleftheriou A (2002) Seascape biodiversity patterns along the Mediterranean and the Black Sea: lessons from the biogeography of benthic polychaetes. Mar Ecol Prog Ser 244:139-152

Babu MN (2003) Implementing Internet GIS with Java based Client/Server Environment. In: Proceedings of Map Asia Conference, 13-15 October 2003, Kuala Lumpur. (available at: www.gisdevelopment.net/technology/gis/ mq03230.htm)

Costello MJ (2000) Developing species information systems: the European register of marine species. Oceanography 13:48-55

Costello MJ, Emblow C, White R (eds) (2001) European register of marine species. A check-list of marine species in Europe and a bibliography of guides to their identification. Patrimoines Naturels, Vol 50, Publications Scientifiques, Muséum national d'histoire naturelle, Paris, p 1-463

Costello MJ, Emblow C, Bouchet P, Legakis A (2006) Gaps in knowledge of marine biodiversity and taxonomic resources in Europe. Mar Ecol Prog Ser 316:257-268 
Decker CJ, O'Dor R (2002) A census of marine life: Unknowable or just unknown? Oceanol Acta 25:179-186

ESRI (Environmental Systems Research Institute) (1994) ARC macro language. ESRI Press, Redlands, CA

Johnson I (2004) Putting time on the map: using TimeMap for map animation and web delivery. GeoInformatics 7:26-29

Laitinen S, Neuvonen A (2001) BALTICSEAWEB: an information system about the Baltic Sea environment. Adv Environ Res 5:377-383

Marshall J (2002) Developing internet-based GIS applications. GIS India 11:16-19

Schalk PH (1998) Management of marine natural resources through by biodiversity informatics. Mar Policy 22:269-280

Tsontos VM, Kiefer DA (2002) The Gulf of Maine biogeographical information system project: developing a spatial data management framework in support of OBIS. Oceanol Acta 25:199-206

Editorial responsibility: Howard I. Browman (Associate Editor-in-Chief), Storebø, Norway,
Valavanis VD (2002) Geographic information systems in oceanography and fisheries. Taylor \& Francis, London

Valavanis VD, Georgakarakos S, Haralabous J (1998) A methodology for GIS interfacing of marine data. In: Proceedings of GIS PLANET 98: international conference and exhibition on geographic information, Lisbon. Imersiva CD-ROM, www.imersiva.com

Valavanis VD, Georgakarakos S, Kapantagakis A, Palialexis A, Katara I (2004a) A GIS environmental modelling approach to essential fish habitat designation. Ecol Model 178:417-427

Valavanis VD, Kapantagakis A, Katara I, Palialexis A (2004b) Critical regions: a GIS-based model of marine productivity hotspots. Aquat Sci 66:139-148

Valavanis VD, Katara I, Palialexis A (2005) Identification of mesoscale thermal fronts using satellite imagery and GIS. Int J Geogr Inf Sci 19:1131-1147

Submitted: February 14, 2005; Accepted: September 6, 2005 Proofs received from author(s): June 14, 2006 